\title{
Evaluation of the Changes in Serum Lipid Profile and Ferritin Concentrations in Relation to Body Ascorbic Acid Status in Healthy Pre- and Postmenopausal Women
}

\author{
P. ÖNER, Ü. Mutlu-TÜrkoĞLU,* and B. ÖMER \\ Department of Biochemistry, Istanbul Medical Faculty, \\ University of Istanbul, Turkey
}

(Received December 27, 1995)

\begin{abstract}
Summary The aim of this work was to study the relationship between body ascorbic acid (AA) status and serum lipid profile and ferritin concentrations in healthy pre- and postmenopausal women. The mean leukocyte and plasma ascorbate values in postmenopausal women were found to be significantly low but within acceptable ranges as compared to premenopausal women. According to these results, plasma and leukocyte AA concentrations decreased after the cessation of ovarian hormone production. In addition, significant increases in total cholesterol, triglyceride and LDL-cholesterol but a significant decrease in HDL-cholesterol were observed in postmenopausal women as compared to premenopausal women. A close positive relationship was found between plasma and leukocyte AA and body iron status in postmenopausal women. The findings were prominent especially in the subgroup of postmenopausal women with low body AA status. Thus, it is concluded that women having low body AA concentrations might have a predisposition for iron depletion.
\end{abstract}

Key Words ascorbic acid, postmenopausal, lipid, lipoprotein, ferritin

Epidemiological studies have shown that the concentration of ascorbic acid (AA; i.e., vitamin C) is higher in females than males and that it declines with advancing age $(1,2)$. Although the health consequences of inadequate vitamin $\mathrm{C}$ status are not well defined except for scurvy, the relationship between AA and lipid, lipoprotein profiles has been well established (1,3-12). It was previously shown that plasma and tissue cholesterol levels and the activity of lipoprotein lipase are sensitive to variations in vitamin $\mathrm{C}$ status $(1,4,5)$. There is some evidence about the enhanced absorption and utilization of non-heme iron in the presence of AA $(13,14)$.

On the other hand, serum lipid and lipoprotein profiles appear to be influenced

* To whom correspondence should be addressed at: Department of Biochemistry, Istanbul Faculty of Medicine, University of Istanbul, Çapa 34390, Istanbul, Turkey. 
by the onset of menopause. In postmenopausal women, a tendency for iron to accumulate in tissue depots was also shown, thereby reflecting an increase in serum ferritin concentration (15).

Considering the sensitivity of iron absorption and lipid, lipoprotein profiles of serum to variations in AA status, we found it of interest to investigate the body AA status and serum lipid and ferritin concentrations in pre- and postmenauposal women not receiving an exogenous AA supplement.

\section{MATERIALS AND METHODS}

A total of 38 healthy adult women participated in this study. The study population was selected from hospital staff and medical students who had similar socio-economical and cultural characteristics and also usual eating habits (i.e., did not go on frequent diets and were not vegetarians). The subjects were classified as follows: 20 healthy women aged 20-35 years (mean 28.9 \pm 3.7 ) with regular menstrual cycles (27-29 days) and not undergoing anovulatory treatment comprised the premenopausal group; and, 18 women volunteers aged 45-65 years (mean 57.8 \pm 5.1 ) who had natural menopause at least two years prior to the study comprised the postmenopausal group.

None of the women were under any medications including iron or AA supplements, oral contraceptives or any hormonal therapy that could influence their blood lipid levels. They were judged healthy on the basis of medical history, and routine laboratory blood and urine tests. All of the participants were non-smokers and non-drinkers or drank alcoholic beverages only occasionally, and none had histories of allergic or anaphylactic diseases. The volunteers were instructed to maintain their usual activity level and consume meals similar in composition for at least three days prior to the study. The composition of diets was 50\% calories from carbohydrates, 35-40\% from fat and 15-20\% from protein. Calorie intakes were established for each woman using standard intakes for sex, age and weight and information about their usual dietary intakes. Pregnant and lactating women were excluded.

For the premenopausal women, blood was drawn at the late luteal phase because cholesterol levels have been reported to be lower by the end of the cycle; and all gonadal steroid functions are at their lowest levels and stable (16). Fasting blood samples taken from pre- and postmenopausal women were subjected to the following analysis. Plasma and leukocyte vitamin $\mathrm{C}$ concentrations were determined immediately by the method of Denson and Bowers (17). After the collection of blood with heparin as the anticoagulant, the AA in the plasma $(\mathrm{mg} / \mathrm{dl})$ was stabilized by the addition of twice the volume of 5\% trichloroacetic acid and determined by spectrophotometric procedures with 2,4-dinitrophenylhydrazine as the chromogen (17).

The determination of AA in the white blood cells (WBC) was performed by the same procedure used for plasma AA (P-AA) analysis after the separation of 
white cells from the plasma by centrifugation at 3,000 rpm. The AA content of the white cells was expressed as $\mu \mathrm{g} / 10^{8} \mathrm{WBC}$. The serum levels of total cholesterol (T-C) and HDL cholesterol (HDL-C) $(\mathrm{mg} / \mathrm{dl})$ were analysed in duplicate by an enzymatic method (Randox). Triglyceride (TG) $(\mathrm{mg} / \mathrm{dl})$ was measured using a WAKO kit. Low-density lipoproteins (LDL) $(\mathrm{mg} / \mathrm{dl})$ were precipitated from serum by the addition of phosphotungstic acid in the presence of $\mathrm{Mg}^{2+}$ ions. HDL-C values were determined enzymatically in the supernatant obtained after centrifugation. LDL-cholesterol (LDL-C) levels were calculated using the following formula (18):

$$
\text { LDL-C }=\text { T-C }-[\text { HDL-C }+(\text { Triglyceride } / 5)] .
$$

Serum iron, iron-binding capacity (IBC) and haematological parameters were measured by automated methods using a Techicon-H 6000 autoanalyzer. Serum ferritin concentration was measured by an enzyme immunoassay kit from BioMérieux (Ref 6908 0) based on a sandwich technique using two monoclonal antibodies.

Statistical evaluations were performed between pre- and postmenopausal women using the Mann-Whitney procedure. The relation between body iron status, serum lipid profile and body AA concentrations were calculated using Pearson's correlation coefficient.

\section{RESULTS}

The mean values for serum lipids and AA levels obtained from the pre- and postmenopausal women are presented in Table 1. T-C, TG and LDL-C levels in the postmenopausal women were found to be significantly higher $(p<0.001)$ than those in the premenopausal women, whereas HDL-cholesterol (HDL-C) decreased significantly in this group $(p<0.01)$. However, the mean values of all parameters were within the normal range.

Plasma and WBC AA levels in the premenopausal women were mean values of $0.64 \pm 0.1 \mathrm{mg} / \mathrm{dl}$ and $28.2 \pm 6.9 \mu \mathrm{g} / 10^{8} \mathrm{WBC}$; ranging from 0.42 to 0.83 and from

Table 1. Mean serum lipid, plasma and leukocyte (WBC) ascorbate levels in preand postmenopausal women (M $\pm \mathbf{S D})$.

\begin{tabular}{lcc}
\hline & $\begin{array}{c}\text { Premenopausal } \\
n=20\end{array}$ & $\begin{array}{c}\text { Postmenopausal } \\
n=18\end{array}$ \\
\hline T-C $(\mathrm{mg} / \mathrm{dl})$ & $153 \pm 29.1$ & $204 \pm 38.8^{* * *}$ \\
HDL-C (mg/dl) & $51.1 \pm 8.0$ & $44.2 \pm 7.8^{* *}$ \\
LDL-C $(\mathrm{mg} / \mathrm{dl})$ & $87.2 \pm 25.7$ & $137 \pm 37.4^{* * *}$ \\
TG $(\mathrm{mg} / \mathrm{dl})$ & $71.1 \pm 21.3$ & $113 \pm 37.7^{* * *}$ \\
Plasma AA $(\mathrm{mg} / \mathrm{dl})$ & $0.64 \pm 0.1$ & $0.56 \pm 0.1^{*}$ \\
WBC AA $\left(\mu \mathrm{g} / 10^{8}\right.$ WBC$)$ & $28.2 \pm 6.9$ & $23.9 \pm 4.0^{*}$ \\
\hline${ }^{*}<0.05,{ }^{* *} p<0.01, * * * p<0.001$ compared with premenopausal women.
\end{tabular}


20.4 to 40.3 , respectively. An individual analysis of the 20 premenopausal women showed that the leukocyte AA concentration for every subject was above the bottom limit of the reference range (reported as $20 \mu \mathrm{g} / 10^{8} \mathrm{WBC}$ ).

Mean plasma and leukocyte AA values in the postmenopausal women were lower than those obtained from the premenopausal women. However, these values remained within the reference ranges $\left(23.9 \pm 4.0 \mu \mathrm{g} / 10^{8} \mathrm{WBC}, 0.56 \pm 0.1 \mathrm{mg} / \mathrm{dl}\right.$ for plasma, ranging from 19.3 to 31.0 and from 0.31 to 0.73 , respectively).

The mean values of body iron status and haematological parameters for the pre- and postmenopausal women are presented in Table 2. Serum iron concentration and iron binding capacity (IBC) in the premenopausal women were not significantly different from those of the postmenopausal women. In contrast, the body iron status, as measured by serum ferritin, for the premenopausal women was significantly lower than in the postmenopausal women $(p<0.001)$. Hemoglobin, hematocrit values and red blood cell (RBC) and WBC counts in the pre- and postmenopausal women were not significantly different between the two groups.

All participating women were divided into two subgroups according to their WBC-AA concentration, which is the best indicator of tissue stores of the vitamin. The following criteria were used for separation of the subgroups: Women with WBC-AA $<25 \mu \mathrm{g} / 10^{8}$ cells composed the low (L) body AA group and those with WBC-AA $>25 \mu \mathrm{g} / 10^{8}$ cells composed the high (H) body AA group. Thus, half of the 20 premenopausal women and 11 of the 18 postmenopausal women made up the L subgroups, while the remaining premenopausal and postmenopausal women made up the $H$ subgroups.

Table 3 shows comparisons of the mean values of serum lipid profile, body iron status and AA concentrations obtained from the pre- and postmenopausal women with low (L) and high (H) body AA concentrations.

In the $L$ subgroups of the pre- and postmenopausal women, changes in body AA concentration were found to be accompanied by parallel changes in HDL-C, serum iron and ferritin levels. Among the measured variables, especially the serum ferritin value decreased dramatically in subgroup $L$ of the postmenopausal women

Table 2. Body iron status and hematological parameters in pre- and postmenopausal women $(\mathrm{M} \pm \mathrm{SD})$.

\begin{tabular}{lcc}
\hline & $\begin{array}{c}\text { Premenopausal } \\
n=20\end{array}$ & Postmenopausal \\
& $104 \pm 29.1$ & $88.8 \pm 23.6$ \\
\hline Serum iron $(\mu \mathrm{g} / \mathrm{dl})$ & $317 \pm 40.2$ & $322 \pm 35.8$ \\
IBC $(\mu \mathrm{g} / \mathrm{dl})$ & $34.7 \pm 15.7$ & $77.2 \pm 47.4^{* * *}$ \\
Serum ferritin $(\mathrm{ng} / \mathrm{ml})$ & $14.2 \pm 1.1$ & $14.6 \pm 1.3$ \\
Hemoglobin $(\mathrm{g} / \mathrm{dl})$ & $42.8 \pm 2.7$ & $44.3 \pm 4.1$ \\
Hematocrit $(\%)$ & $4.9 \pm 0.4$ & $5.1 \pm 0.4$ \\
RBC $\left(\times 10^{12} /\right.$ liter $)$ & $6.9 \pm 1.5$ & $7.2 \pm 2.4$ \\
WBC $\left(\times 10^{9} /\right.$ liter $)$ &
\end{tabular}

$* * * p<0.001$ compared with premenopausal women. 
as compared to subgroup $\mathbf{H}$ of the same group.

As for a comparison of the two groups of women with high body AA status (H subgroups); the LDL-C, T-C, TG and serum ferritin values of the postmenopausal women were significantly higher than those observed for the premenopausal women ( $p<0.01$ for LDL-C, T-C, TG and $p<0.001$ for ferritin). T-C, TG, LDL-C and serum ferritin values in subbgroup $\mathrm{L}$ of the postmenopausal women showed significant increases $(p<0.05$ for T-C, LDL-C and serum ferritin and $p<0.01$ for TG), whereas the HDL-C and serum iron were found to have decreased as compared to subgroup L of the premenopausal women; but only the HDL-C value was significant $(p<0.01)$ (Table 3$)$.

The correlation coefficients between plasma and leukocyte AA concentrations and some measured variables for postmenopausal women are shown in Table 4. Body AA status was found to be well correlated with the serum iron, ferritin, IBC and HDL-C levels. Serum ferritin reached the highest significance $(p<0.001)$, followed by serum iron, IBC $(p<0.01)$ and HDL-C $(p<0.05)$ when correlated with WBC-AA. In contrast, serum iron and ferritin reached the highest degree of significance $(p<0.001)$, followed by IBC and HDL-C $(p<0.01)$ when correlated

Table 3. Comparison of lipid profile and body iron status in pre- and postmenopausal women with low (L) and high (H) AA concentrations (M $\pm \mathrm{SD})$.

\begin{tabular}{|c|c|c|c|c|}
\hline & \multicolumn{2}{|c|}{ Premenopausal } & \multicolumn{2}{|c|}{ Postmenopausal } \\
\hline & $\mathrm{L}(n=10)$ & $\mathbf{H}(n=10)$ & $\mathrm{L}(n=11)$ & $\mathrm{H}(n=7)$ \\
\hline Plasma AA (mg/dl) & $0.59 \pm 0.11$ & $0.70 \pm 0.09$ & $0.50 \pm 0.13$ & $0.65 \pm 0.06$ \\
\hline WBC AA $\left(\mu \mathrm{g} / 10^{8}\right.$ cells $)$ & $22.7 \pm 1.7$ & $33.8 \pm 5.5$ & $21.1 \pm 1.8$ & $28.3 \pm 1.8^{\#}$ \\
\hline $\mathrm{T}-\mathrm{C}(\mathrm{mg} / \mathrm{dl})$ & $161 \pm 32.1$ & $144 \pm 24.5$ & $194 \pm 30.8^{*}$ & $218 \pm 47.7^{* *}$ \\
\hline HDL-C (mg/dl) & $50.3 \pm 7.8$ & $52.1 \pm 8.5$ & $41.2 \pm 6.8^{* *}$ & $48.9 \pm 7.2$ \\
\hline LDL-C (mg/dl) & $94.9 \pm 27.7$ & $79.7 \pm 22.3$ & $130 \pm 29.1 *$ & $148 \pm 48.1^{* *}$ \\
\hline $\mathrm{TG}(\mathrm{mg} / \mathrm{dl})$ & $80.6 \pm 21.9$ & $61.6 \pm 16.8$ & $117 \pm 39.7^{* *}$ & $106 \pm 36.4^{* *}$ \\
\hline Serum iron $(\mu \mathrm{g} / \mathrm{dl})$ & $98.0 \pm 23.2$ & $109 \pm 34.5$ & $79.0 \pm 21.0$ & $104 \pm 19.8$ \\
\hline Serum ferritin $(\mathrm{ng} / \mathrm{ml})$ & $34.3 \pm 11.0$ & $35.2 \pm 20.0$ & $51.5 \pm 20.3^{*}$ & $118 \pm 50.7$ \\
\hline IBC $(\mu \mathrm{g} / \mathrm{dl})$ & $322 \pm 41.2$ & $313 \pm 41.0$ & $339 \pm 32.7$ & $296 \pm 22.4$ \\
\hline \multicolumn{5}{|c|}{$\begin{array}{l}{ }_{p} p<0.05,{ }^{* *} p<0.01, * * * p<0.001,{ }^{\sharp} p=0.05 \text {, compared with corresponding sub- } \\
\text { groups of premenopausal women. }\end{array}$} \\
\hline & \multirow{2}{*}{\multicolumn{2}{|c|}{ WBC-AA }} & \multirow{2}{*}{\multicolumn{2}{|c|}{ P-AA }} \\
\hline & & & & \\
\hline & $r$ & $p$ & $r$ & $p$ \\
\hline Serum iron & 0.638 & $<0.01$ & 0.764 & $<0.001$ \\
\hline Serum ferritin & 0.825 & $<0.001$ & 0.698 & $<0.001$ \\
\hline IBC & -0.623 & $<0.01$ & -0.638 & $<0.01$ \\
\hline HDL-C & 0.520 & $<0.05$ & 0.638 & $<0.01$ \\
\hline
\end{tabular}

Vol. 43, No. 1, 1997 
with plasma AA. Among the measured variables, only IBC was negatively correlated with body AA status. No significant correlations were seen between the AA status and T-C, LDL-C and TG concentrations. In addition, the body AA status in premenopausal women was not significantly correlated with lipid profiles, serum iron, ferritin or IBC (not shown).

\section{DISCUSSION}

This study indicates that the mean leukocyte and plasma ascorbate concentrations observed in the postmenopausal women were significantly lower than those observed in the premenopausal women. However, the values were within the reference ranges. According to our results, body AA concentrations decrease after menopause in which ovarian hormone production ceases. This finding is in agreement with previous reports in which decreased AA levels were observed with advancing age $(2,6,19)$. However the lowered AA status in postmenopausal women could not be related to poorer vitamin intake, but could have resulted from enhanced metabolic turnover and/or probably from the impaired absorption of AA as suggested previously (20). The body status of AA was determined by measuring both plasma and leukocyte AA concentrations. Plasma AA is a fairly good measure of both intake and body status of AA (6), whereas leukocyte AA is believed to reflect tissue stores and the long-term status of the vitamin more accurately (21).

As expected, the serum T-C, TG and LDL-C levels in the postmenopausal women were significantly higher, whereas HDL-C was lower within the normal range as compared to young women. These findings are also in good agreement with the related data in literature $(22,23)$.

In our study, we found a positive correlation between plasma and leukocyte AA levels and serum HDL-C $(p<0.01$ and $p<0.05$ respectively) in postmenopausal women, but we did not observe any relationship with HDL-C in premenopausal women. Therefore, we suggest that a high level of HDL-C in healthy young women may not be related to body AA status but related to other factors such as circulating oestrogens. The positive correlations found between plasma and leukocyte AA and HDL-C concentrations after menopause have also been reported by other investigators $(3,6-8)$. In addition, the body AA status in pre- and postmenopausal women was found to be inversely related with TG concentration. Little is known about the effect of AA on plasma TGs in normal subjects. When all subjects were divided into subgroups of low and high body AA concentrations, the serum TG levels fell as ascorbate concentrations rose. This negative correlation might be important with regard to susceptibility to coronary heart disease (CHD), since serum TG has been suggested to be a strong predictor of CHD in women over 50 years (24).

The available reports on the relationship between AA and lipid, lipoprotein profiles in humans demonstrate conflicting results and differ from our study. Most of the previous studies involved vitamin $\mathrm{C}$ intake (9-11). Few of them are about 
the relationship between body $\mathrm{AA}$ and lipid profiles $(12,21)$. In one report, the amount of samples studied was very small, and there was a positive correlation between leukocyte AA and serum cholesterol (12), whereas the other report states a negative correlation between these parameters (21). In contrast, others refute such an association (9-11).

On the other hand, the haematological parameters (haematocrit, hemoglobin, red and white blood cell counts) were not significantly different between the preand postmenopausal women. We therefore conclude that a low body AA status within the reference range following menopause does not affect erythropoetic activity.

The relationship of AA to iron status and metabolism has not been studied as adequately as the relationship of vitamin $\mathrm{C}$ to lipid, lipoprotein profiles. However, some studies about the enhancing effect of AA on the absorption of non-heme iron have been reported $(13,14)$.

A general analysis of all the postmenopausal women showed a non-significant decline in serum iron but a significant rise in serum ferritin as compared to the premenopausal women. The decline in serum iron was parallel with the decline in plasma and leukocyte AA levels. In contrast, we could not observe any relation between plasma and leukocyte AA and body iron status in the young women. This could possibly be attributed to the differences in the duration and amount of menstrual bleeding, and perhaps in part to nutritional habits. High serum ferritin with a wide intraindividual variation in its concentration in postmenopausal women is consistent with some previous reports (25-27).

An individual analysis of the 18 postmenopausal women in this study showed a close relationship between plasma and leukocyte AA and body iron status. In subgroup $L$ of the postmenopausal women (consisting of 11 subjects), serum iron and ferritin values showed a parallel decrease with the decline in body AA status, whereas IBC was at the highest level. In contrast, the remaining postmenopausal women (consisting of seven subjects) with high body AA levels (subgroup H) also had high serum iron and ferritin levels with low IBC. Thus, it can be assumed that the body AA and iron status are closely related after menopause, and one might expect to observe a low serum iron level and iron status as measured by serum ferritin in women having plasma and leukocyte AA levels below the reference range. Highly significant positive correlations between body AA status and serum iron ( $r=0.638$ verses WBC AA, $p<0.01, r=0.764$ verses plasma AA, $p<0.001$ ) and also serum ferritin $(r=0.825$ verses WBC AA, $r=0.698$ verses plasma AA, $p<$ 0.001 ) in postmenopausal women, support this suggestion. Therefore, it should be taken into consideration that iron depletion might be observed in postmenopausal women with AA deficiency.

In conclusion, body AA levels appear to decrease after a menopausal period in which ovarian hormone production ceases. Although changes in lipid, lipoprotein profiles associated with the parallel decrease in body AA status after menopause do not represent a critical level for producing coronary heart disease risk, women 
having low body AA concentrations might have a predisposition for iron depletion, and therefore, an AA rich diet is necessary for the elderly to have an optimal life-style.

The authors thank the Research Fund of the University of Istanbul for the financial support.

\section{REFERENCES}

1) Itoh, R., Yamada, K., Oka, J., Echizen, H., Suyama, Y., and Murakami, K. (1990): Serum ascorbic acid and HDL-cholesterol in a healthy elderly Japanese population. Int. Vit. Nutr. Res., 60, 360-365.

2) Sasaki, R., Kurokawa, T., Kobayashi, T., and Tero-Kubota, S. (1983): Influences of sex and age on serum ascorbic acid. Tohoku J. Exp. Med., 140, 97-104.

3) Jaques, P. (1992): Relationship of vitamin C status to cholesterol and blood pressure. Ann. N. Y. Acad. Sci., 669, 205-214.

4) Uchida, K., Nomura, Y., Takase, H., Tasaki, T., Seo, S., Hayashi, Y., and Takeuchi, N. (1990): Effect of vitamin C depletion on serum cholesterol and lipoprotein levels in ODS (od/od) rats unable to synthesize ascorbic acid. J. Nutr., 120, 1140-1147.

5) Jacques, P. F., Hartz, S. C., McGandy, R. B., Jacob, R. A., and Russel, R. M. (1987): Ascorbic acid, HDL and total plasma cholesterol in the elderly. J. Am. Coll. Nutr., 6, 169-174.

6) Bates, C. J., Burr, M. K., and Leger, A. S. (1979): Vitamin C, high density lipoproteins heart disease in elderly subjects. Age Aging, 8, 177-182.

7) Dallal, G. E., Choi, E., Jaques, P., Schaeffer, E. J., and Jacob, R. A. (1989): Ascorbic acid, HDL-cholesterol and apolipoprotein A-I an elderly Chinese population in Boston. J. Am. Coll. Nutr., 8, 69-74.

8) Burr, M. L., Bates, C. J., Sweetham, P. M., and Barasi, M. E. (1982): Plasma ascorbate and HDL-cholesterol in women. Hum. Nutr. Clin. Nutr., 36C, 399-400.

9) Khan, A. R., and Seedarne, F. A. (1981): Effect of ascorbic acid on plasma lipids and lipoproteins in healthy young women. Atherosclerosis, 30, 89-95.

10) Peterson, V. E., Crapo, P. A., Weininger, J., Ginoberg, H., and Olefsley, J. (1975): Quantification of plasma cholesterol and triglyceride levels in hypercholesterolemic subjects receiving ascorbic acid supplements. Am. J. Clin. Nutr., 28, 584-587.

11) Wahlberg, G., and Walldius, G. (1982): Lack of effect of ascorbic acid on serum lipoprotein concentrations in patients with hypercholesterolemia. Atherosclerosis, 43, 283-288.

12) Davies, J. D. G., and Newson, J. (1974): Ascorbic acid and cholesterol levels in pastoral peoples in Kenya. Am. J. Clin. Nutr., 27, 1039-1042.

13) Hunt, J. R., Mullen, L. M., Lykken, G. I., Gallagher, S. K., and Nielsen, F. H. (1990): Ascorbic acid: Effect of ongoing iron absorption and status in iron depleted young women. Am. J. Clin. Nutr., 51, 649-655.

14) Bothwell, M. J., Baynes, R. D., MacFarlane, B. J., and MacPhail, A. P. (1989): Nutritional iron requirements and food iron absorption. J. Intern. Med., 226, 357-365.

15) Ahluwalia, N., Lamni-Keefe, C. I., Haley, N. R., and Beard, J. K. (1993): Day to day variation in iron status indexes in elderly women. Am. J. Clin. Nutr., 57, 414-419. 
16) Lussier-Cacan, S., Xhignesse, M., Desmaris, J. L., Davignon, J., Kafrissen, M. E., and Chapdalaine, A. (1991): Cyclic fluctuations in human serum lipid and apolipoprotein levels during the menstrual cycle: Comparison with changes occurring during oral contraceptive therapy. Metabolism, 40, 849-854.

17) Denson, K. W., and Bowers, C. F. (1961): The determination of ascorbic acid in white blood cells. A comparison fo W.B.C. ascorbic acid and phenolic acid excretion in elderly patients. Clin. Sci., 21, 157-162.

18) Burstein, M., and Samaille, J. (1960): On a rapid determination of the cholesterol bound to the serum and lipoproteins. Clin. Chim. Acta, 5, 609-611.

19) Burr, M. L., Elwood, P. C., Hole, D., Hurley, R. J., and Hughes, R. E. (1974): Plasma and leukocyte ascorbic acid levels in the elderly. Am. J. Clin. Nutr., 27, 144151.

20) Burr, M. L., Sweetham, P. M., Hurley, R. J., and Powell, G. H. (1974): Effect of age and intake on plasma ascorbic acid levels. Lancet, 1, 163-164.

21) Cerna, D., and Ginter, E. (1978): Blood lipids and vitamin C status. Lancet, 1, 10551056.

22) Applebaum-Bowden, D., McLean, P., Steinmetz, A., Fontana, D., Matthys, C., Warniek, G. R., Cheung, M., Albers, J. J., and Hazzard, W. R. (1989): Lipoprotein, apolipoprotein and lypolytic enzyme changes following estrogen administration in postmenopausal women. J. Lipid Res., 30, 1895-1906.

23) Matthews, K. A., Meilahn, E., Kuller, L. H., Kelsey, S. F., Caggiula, A. W., and Wing, R. R. (1989): Menopause and risk factors for coronary heart disease. N. Eng. J. Med., 321, 641-646.

24) Lapidus, L., Bengstsson, C., Lindguist, O., Sigurdsson, J. A., and Rybo, E. (1985): Triglycerides-main lipid risk factor for cardiovascular disease in women? Acta Med. Scand., 217, 481-489.

25) Borel, M. J., Smith, S. M., Derr, J., and Beard, J. L. (1991): Day to day variation in iron status indices in healthy men and women. Am. J. Clin. Nutr., 54, 729-735.

26) Herbert, V. (1990): Nutritional anemias in the elderly, in Nutrition and Aging, ed. by Prinsley, D. M., and Sandstead, H. H., Alan R Liss, New York, pp. 203-207.

27) Imbert, M., Priolet, G., Rymer, J. C., and Sultan, C. (1987): Reévaluation des stratégies pour le diagnostic des carences martiales. Ann. Biol. Clin., 45, 541-545. 